\title{
Anatomy of a Rhetorical Gesture
}

\author{
Anatomia de um gesto retórico
}

\section{Gonzalo Javier Martínez García}

Universidad de Talca, Talca, Chile

gmartinez@utalca.cl

\begin{abstract}
The article analyzes a rhetoric gesture that frequently appears in tonal and post tonal repertoires, and starting from an analysis by Patrick McCreless (2006) postulates that the gesture is more limited than what the author proposes in this reference, reducing it to three stages related with the process of expectations. For the analysis, it checks the definitions offered by renowned investigators of gesture in general and rhetoric gesture in particular. The analysis is based in concepts that imply: the participation of the body in the musical audition, the attributes of significances, the metaphoric audition and, finally, the model of expectations proposed recently by David Huron. Finally, it analyses the instances of the gesture that appear in the pianistic and symphonic repertoire from the eighteenth century up to the beginning of the twentieth century.
\end{abstract}

Keywords: Rhetoric gesture; personified audition; metaphoric audition; gestural analysis; musical rhetoric.

Resumo: 0 artigo analisa um gesto retórico que aparece frequentemente no repertório tonal e pós-tonal, a partir de uma análise de Patrick McCreless realizada em 2006 sobre o mesmo assunto. Defende-se a ideia de que o gesto é mais limitado do que o autor propõe nessa referência, reduzindo-o a três fases relacionadas com o processo da expectativa. Para realizar a análise foram revisadas as definições de gesto em geral e de gesto retórico em particular, propostas por renomados pesquisadores. A análise é baseada em conceitos que envolvem: a participação do corpo na audição de música, a atribuição de significado, a audição metafórica, e, finalmente, o modelo de expectativas recentemente proposto por David Huron. Os casos de gesto que aparecem no repertório pianístico e sinfônico, desde o século XVIII até o principio do século XX são investigados.

Palavras-chave: gesto retórico; audição "encarnada"; audição metafórica; análise gestual; retórica musical.

Submission date: 14 August 2017

Final approval date: 26 March 2018

\section{1 - Introduction}

Patrick McCreless (2006) wrote an interesting chapter in a book about the meaning of music. His contribution was focused on a study about musical gesture, starting from the gesture that set the climax of the first section of Electronic Study $N^{\circ} 1$, an electro-acoustic piece by Mario Davidovsky composed in 1960. The author puts forth several instances in which similar cases are present in romantic, post romantic, contemporary and jazz music for piano. He describes the gesture as it appears in Figure 1, analyzing it as a sequence of four phases numerically identified: a phase of ascent in the register accompanied by increased tension, a phase of compensation in said movement, a phase in which a sonorous and powerful sound accent can be perceived, and a phase of distension produced by the extinction of the resonance As shown in Figure 1, the tension rises up to point 3 and then, starting from there, decreases in that direction. 


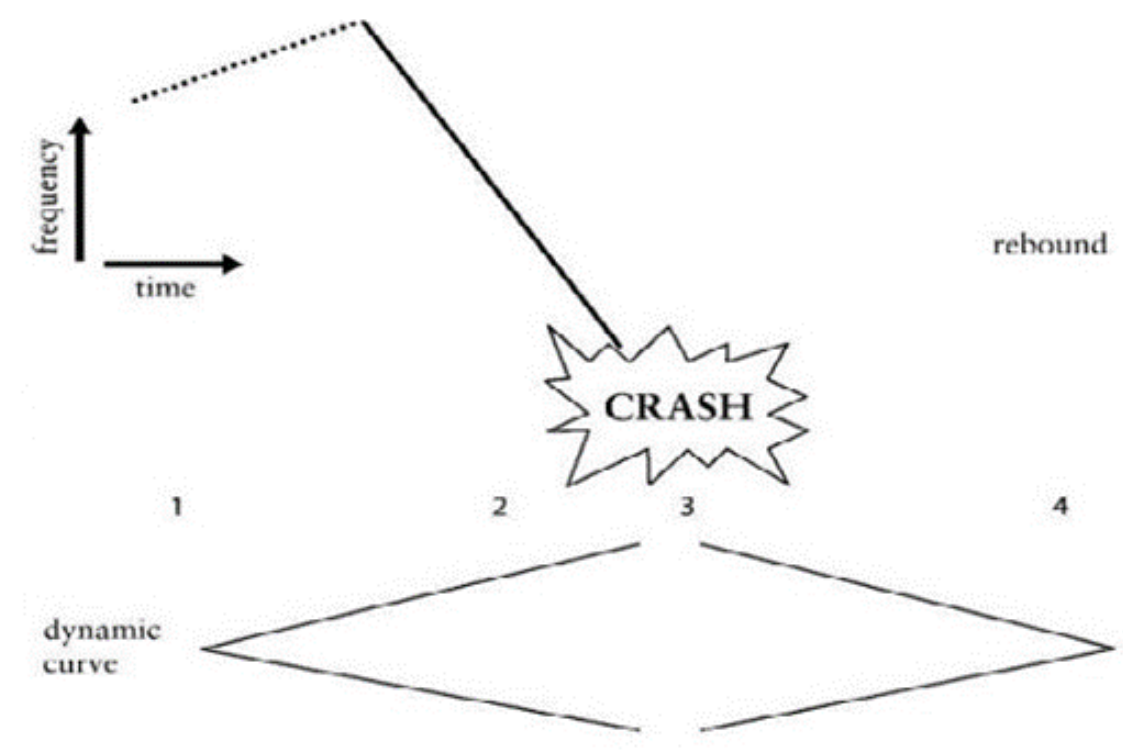

Figure 1: Diagram of the gesture MCCRELESS (2006, p.12).

I do not disagree with the analysis of this author, but in this article I argue that said gesture can be considered as a variation of a more bounded rhetorical gesture, which is quite present in romantic music for piano, although not limited to it. As we will see later on, it is a variation because the gesture consists mainly of the first three phases of the example, and it is rhetorically used to highlight cadences and to prepare the appearance of themes. In this article I propose that the musical characteristics, the contributions of auditory psychology and the process of musical expectation characterize this gesture as a rhetorical strategy. I describe the gesture, explaining some conceptual foundations that sustain my analytical vision. I argue some recent ideas about the embodied audition and the metaphor, meaning and expectations in music which are ideas that I use to substantiate my argument - and I analyze moments of the gesture that belonged to styles dating from the 18th century up until the beginning of the 20th century, grouped in two categories: prototypical gestures and variants.

\section{2 - Theory of musical gestures}

The use of the concept of gesture in music could be considered from multiple perspectives; therefore it is not surprising that there is no consensus among researches when it comes to its meaning. ${ }^{1}$ In my opinion, this can be explained if we consider it as a metaphor: a concept used to describe facial and/or body movements, which is metaphorically projected on music. Secondly, it is not a concept that has been a part of the traditional formal theories, which would be the case with the concepts of motif and theme. ${ }^{2}$ What do we mean with the word "gesture?"

\footnotetext{
${ }^{1}$ And this does not only happen in the case of music. For example, we should take into account the definition that FLUSSER (2014) gave for the gestures in different areas of human life: for him they were movements of the body or tools that were used by the body for which there are no satisfactory casual explanations.

${ }^{2}$ While the term "gesture" frequently appears in musical analysis, it is not used in a formal way, as an explicit construct of a theory about form. DUDEQUE (2013, p.86) acknowledges three ordinary uses of the term: as a formal function (for example, "an opening gesture"), as a rhetorical function ("fanfare gesture"), and as a stylistic topic, acknowledging that it is not common to penetrate its function or to specify its nature, given that it is always used generically. This author proposes an inclusive definition of gesture, but his intention is to delimit a
} 
It is a descriptive term, a sign that means something to somebody but that, when it is used metaphorically its meaning depends of the perspective of the one that uses it. Even so, GRITTEN and KING (2006, p.xx) have proposed a definition of the concept strategically inclusive. For them, there is a consensus amongst the researchers regarding gesture, which they describe as: "[...] a movement or change in state that becomes marked as significant by agent." This definition is in its nature widely extensive and semiotic, since it involves a signifier, an interpreter and a meaning. As these authors point out later, this movement is a process of ascription in which a stimulus is interpreted by someone as a gesture.

For HATTEN (2004, p.95), on the other hand, the musical gestures are a "(...) significant energetic shaping of sound through time"3. The meaning of the gesture emerges in the sense that it arises from an intermodal perception. When we interpret them, our sensorimotor system participates as a whole 4 . The prototypical gestures are perceived within the boundaries of the perceptual present (short term memory) and are interpreted through imagination and the figure-formation process of the gestalt (2005, p. 14-28). He interprets the translation of the human gestures within music based on the existence of an analogy that forms what it is called a "virtual gravitational field" (2005, p.16). Here, a parallel occurs between the forces that act upon the human body and the forces that are projected on music, forming a process that is compelled by our imagination and our cognitive abilities ${ }^{5}$.

BEN-TAL (2023, p.251-252) has recently proposed an interesting definition of gestures, in which he understands them as "expressive gestural units", depicting them as short, selfcontained, with clearly defined initiations and terminations. They are also characterized by the ability to express an idea or an emotion quite clearly, always truthful to the perspective of the auditor. What is interesting about what Ben-Tal proposes is that he explicitly differentiates gesture from motif and figure. The motif is different because it is used as composition material through the variation operations - which does not occur with the gesture - while the figure, understood as ornamentation, does not have the expressive component that is highlighted by the gesture.

But these definitions are explicitly extensive and they entail a problem when it comes to applying them to specific cases. For example, in the definition of Ben-Tal it is not clear what the gestural component of these expressive units is. On the other hand, the definition of Hatten is quite general as well since it does not clarify either in which aspect lies the energy of the musical

\footnotetext{
concept used in music analysis that is particularly difficult to approach from the point of view of the formal phraseology. In fact, he recognizes four kinds of gestures: motivic/thematic, cadential, textural, and rhythmic (2013, p.87). Dudeque's position is different from mine when it comes to the fact that it does not start in the auditor, but rather in the object of analysis, and therefore I do not use his definition of gesture. I position myself as an analyst of the esthetic, assuming the tripartition of the semiologic process proposed by NATTIEZ (1990, p.10-16): poietic dimension (process of creation), esthetic dimension (perception process understood in an active way regarding the participation of the auditor), and trace (the material support of music, that is, sound, score).

${ }^{3}$ The italics are part of the original text.

${ }^{4}$ In fact, in another of his works, HATTEN (2004, p.94) characterizes musical gestures as "synthetic gestalts", in which the synthesized elements include timbres, articulations, dynamics, tempos, amongst other parameters, and its coordination with several syntactic levels.

${ }^{5}$ Quite interestingly, Hatten concludes that this analogy between human gestures and those that are projected on music imply the concept of "musical agent", especially when a series of gestures suggest a directed movement, given the parallelism with the intentionality that we can find behind human gestures.
} 
gesture. Therefore, phrases, great sections, or even an entire musical piece ${ }^{6}$ could be a part of his definition.

For KÜHL (2011) the musical gestures involve a double projection: the phrase signifies a gesture, and this gesture projects an emotional meaning. Therefore he considers them as the key to understanding the meaning of music. The gestures are complex and dynamic gestalts, which are formed in a very basic and generic state of cognition, and they imply a metaphorical projection from space (the melodies go up or down, implying a profile), from temporality (we imagine the movement going towards a goal), and from the body (we feel the movement towards and from these events). It is from these associations that we interpret it. This is consistent with the opinion of HATTEN $(2004$, p.95) regarding the fact that the perception of sound gestures imply a series of abilities that include being able to relate music to affective, sensory and motor areas from human experience.

Kühl also criticizes how important semioticians of music such as Tarasti and Tagg, along with everyone based on the peircean semiotics, have handled the understanding of gesture. His main critic lies on the lack of clarity of Peirce's theory, which hinders the application and interpretation in music, specially taking into account that, by itself, this is a quite difficult field to clarify in terms of language. What Kühl proposes is to apply Saussure's semiotic to music, which is clearer in this sense. Basically, he proposes to analyze the sign function of the gesture applying the duality of signifier-signified: the musical phrase acts as a signifier, with produces the construction of the gesture in the mind of the auditor, who would work as the signified in the process of semiology. In this level, the phrase acts like a labeling aspect of the musical meaning, and from there it carries on with the process of infinite semiosis, in which the meaning becomes at the same time its signifier.

As we can see, all these authors work in varying degrees within the paradigm of embodied cognition. There are several theories within this paradigm that allow understanding the musical and psychological efficiency of the gesture. I find some of them particularly relevant for my position statement, and I name them under the title of "listening as". Said theories belong to the works of SPITZER (2004), HATTEN $(2004,2005,2006)$, COX $(1999,2006,2011)$, KÜHL (2011) and LARSON $(2006,2012)^{7}$. Basically, these theories propose that musical cognition corresponds to a dynamic process in which we hear the sound stimuli as if they were actions that occur in the physical world, including our body involvement, through different metaphorical projections. The philosopher Roger Scruton gives an excellent example of this process, when he states that, in musical audition:

“... one and the same experience takes sounds as object, and also something that is not and cannot be sound - the life and movement that is music. We hear this life and movement in the sound, and situate it in an imagined space, organized, as is the phenomenal space of our own experience, in terms of "up" and "down," "rising" and "falling," "high" and "low..." (quoted by SPITZER, 2004, p.9).

What Scruton states is that we project in music our vital experiences, and we mentally situate the sounds that we listen in an imagined space with special attributes, which allow us "to listen

\footnotetext{
${ }^{6}$ HATTEN's (2004, p.95) conception originates from his general definition of gesture: "[...] significant energetic shaping through time", which he acknowledges was conceived to include all kinds of human movements that could possibly be significant.

${ }^{7}$ While Spitzer and Larson explicitly use the terms "to listen as" to explain their theory of bodily musical cognition, Cox implies the same by stating his "mimetic Hypothesis", in which he listen to music as if we were producing it ourselves through a process of empathy, and Kühl explicitly considers in his theory the phenomenon of metaphorical projection in the perception of the gesture. Therefore I understand those theories as a corpus with a base in common.
} 
as" if a melody was going up and down, as if things were moving closer or farther away, as if we could come to a resting place, etc. These projections are possible because of the presence of patterns-images, pre-conceptual structures that form in the earliest experiences of infancy, particularly as a result of our relationship with adults. They are the foundation of our experiences with the physical world and with our own body (JOHNSON, 1990).

In my opinion, the key lies in understanding the gesture that I am analyzing as a rhetorical strategy. López Cano defines the rhetorical figure in music as:

“... una operación que desvía una expresión musical del uso gramatical común. Es una desviación respecto de las normas habituales de la música. Es el proceso de transgresión a la regla musical que provoca que, en un contexto determinado, la forma «correcta» de la realización musical, ceda su lugar a otra de carácter sorpresivo, inesperado, inusitado y extracotidiano que se propone ofrecer al discurso musical belleza, refinamiento, elegancia, atractivo y, sobre todo, se propone mover los afectos del oyente..." (LÓPEZ CANO, 2012, p.92) ${ }^{8}$.

While López Cano is referring to the baroque rhetoric, his definition allows us to clarify other aspects of the gesture that I am studying. The key of his definition is that the rhetorical figure is a transgression of the norm. So, what does this gesture transgress? Basically it transgresses the norm established by the musical behavior that comes before it, regarding the register, dynamic, melodic breadth, rhythmic activity, timbre, etc. In other words, the gesture differentiates itself from what comes before it, becoming a segment that is perceived as if directed towards an objective, indicating a point of arrival.

Hatten specifically organizes the musical gestures according to their functions. Amongst them all, his definition of "rhetorical gesture" is quite relevant for this article, which "[...] marks a disruption in the unmarked flow of events at any level of the musical discourse" (HATTEN, 2005, p.20). The parallelism with the conception of López Cano that we referred to earlier is remarkable. The idea that the gesture would emphasize (mark) a segment within the musical flow is similar to the idea that the gesture "transgresses" the behavior of the music by arising and "denoting" a cadence. From this perspective, I define the kind of gesture that I am analyzing in this article as a cadential segment that produces a change in the direction of the melodic profile leading the attention of the auditor to a point of arrival ${ }^{9}$, specially marked in a rhetorical fashion through processes of tension and distension in different parameters.

The above can be seen clearly in the Figure 2, in which there is a rendering of the gesture that leads to the re-exposition of the second theme of the Ballade op. 23 by Chopin. The gesture is preceded by a billowy melodic profile of great breadth, with the A6 reiterating as a high-pitched limit twice in the previous bars, the dynamic $f f$ and the fast rhythmic figuration ${ }^{10}$.

\footnotetext{
8 “ $[. .$.$] an operation that deviates a musical expression from the ordinary grammatical use. It constitutes a deviation from the customary$ norms of music. It is the process of transgression to the musical rule that provokes that, in a given context, the «correct» way of the musical realization gives way to another, which is surprising, unexpected, unusual and uncommon, and is there to offer beauty, refinement, elegance and appeal to the musical discourse, and, above all, is there to shake up the affections of the listener."

${ }^{9}$ From this perspective, when I am writing about the meaning of gesture I am referring to its intrinsic meaning, intra-musical, assuming the polarity of intrinsic/extrinsic stated by NATTIEZ (1990, p.111-127). However, and according to AGAWU (2012, p.59-61), I also consider that ultimately this polarity is tricky, because, as we have seen as far as it is concerned with bodily cognition, the musical meaning arises from the perception of sounds and from our internal world which is by definition and in its natur, extra-musical.

${ }^{10}$ For the analysis of the register I have the habit of numbering the octaves from the central C of the piano as C4. The higher octaves of said pitch are numerically named in an ascending order, and the inferior bass ones in a descending order.
} 


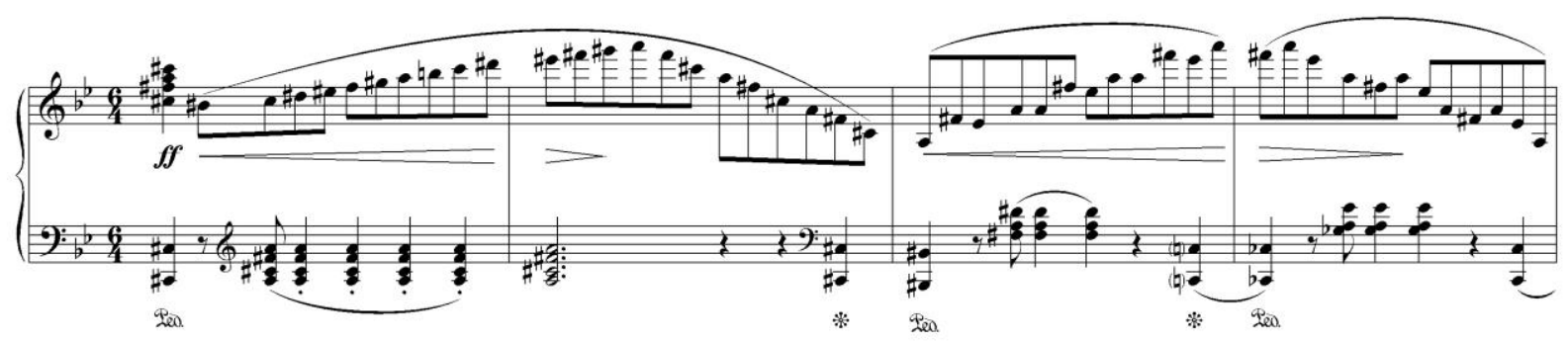

Phase 1 Phase 2
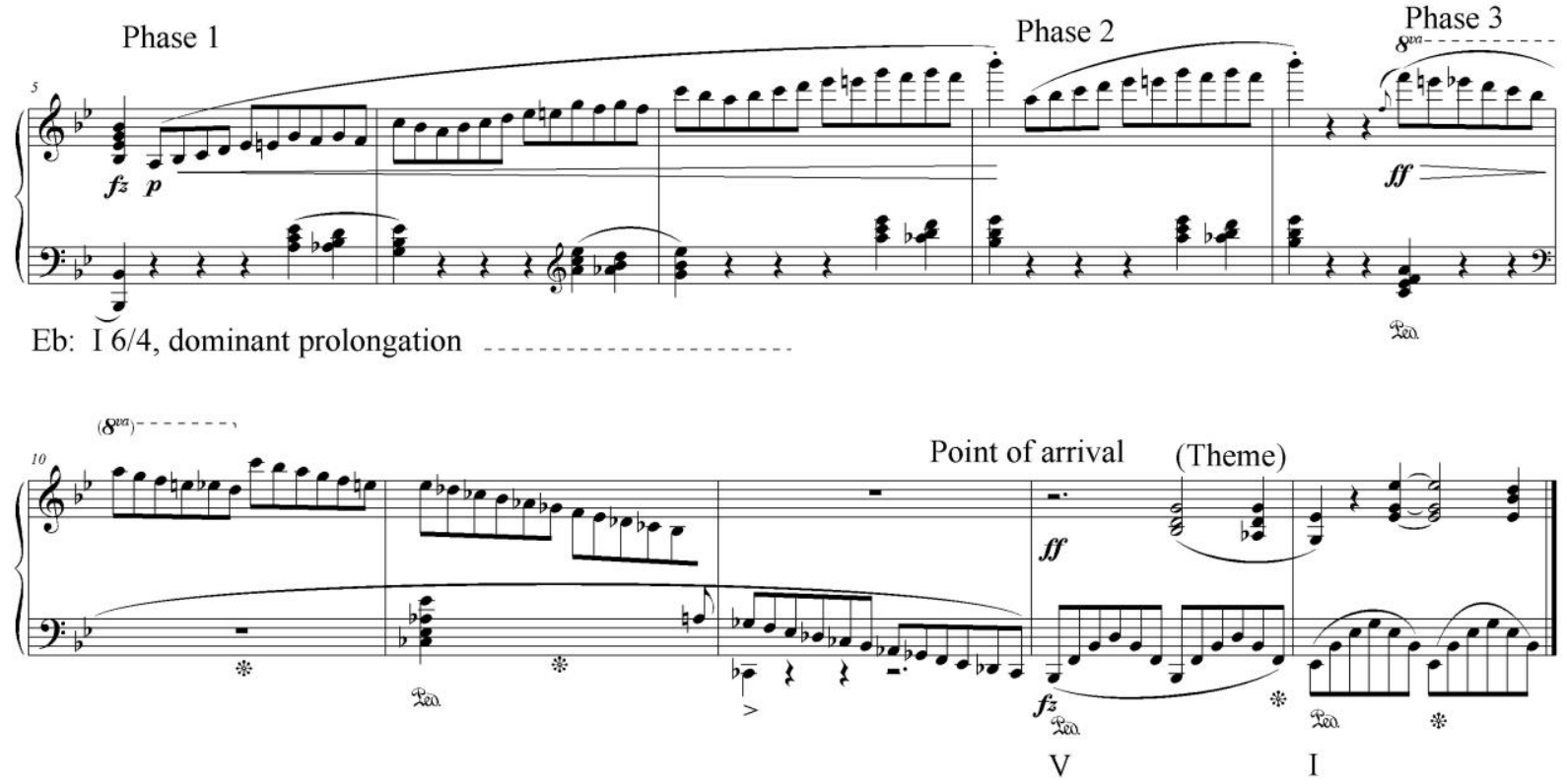

Figure 2: Rhetorical gesture in Chopin's Ballade No. 1, m.154-167

The beginning of the gesture is clearly indicated by a chord in sforzatto, a surprising leap to the dynamic $p$, and the harmonic link from a dominant - named by PISTON (1998, p.404) as a "swiss sixth chord" or a "augmented double fourth chord" - to the I 6/4. The melody starts with the $\mathrm{A} 3$, in the second pulse of the chord 58. The breadth of the gesture is greater than in the previous melody, leading emphatically (by repetition) to $\mathrm{B} 6$, and descending to $\mathrm{Bb} 1$. In the 160 and 162 chords (first pulse) the register stabilizes in the B6, including a pause that is loaded with tension by the interruption of the melodic flow in the high-pitched register, without reverting the melodic direction. The descent is produced from a higher pitched musical note (the F7) and, while it covers half a chord more than the ascent (three and a half chords), it is perceived as faster since it consists completely on a descending line that covers a wider range of breadth, unlike the ascent that had small instances of melodic reversion. The dynamic curve corresponds exactly to the one that covers the points 1 to 3 of the example of McCreless: both from the point of view of the dynamic as from the register, the ascent implicates a significant increase of tension, which remains until the end of the gesture, specially perceived by the conscience of the auditor as a point of arrival. The harmony acts complementarily, prolonging the tension: the gesture is supported entirely by an extension of the dominant function of the $\mathrm{Eb}$, from the I6/4, passing through the iv6, until $\mathrm{V}$, which introduces the accompaniment of the 
second theme ${ }^{11}$. That is to say, the harmony of the gesture implicates a cadential pattern characteristic of the dissonance-resolution but within the dominant. In the descent, the recession is compensated by the quickness of the melodic descent which acts in a complementary way regarding both the dynamic and the harmony so it can maintain the tension ${ }^{12}$. Therefore, most of the parameters implicate a progressive process towards the end of the gesture, the point of arrival of the melodic descent, which points out a notorious shift of the formal function. This way, the music stabilizes itself with an unequivocal figure of accompaniment so it can give way to the theme.

The gesture that I am studying takes place structurally in the micro-level of the form ${ }^{13}$ and it can be considered as a rhetoric realization of a cadence, which means that its efficiency relies not only on the process of articulated closure by the syntactic or primary parameters but also on the junction of said parameters with the statistic or secondary parameters (MEYER, 2000, p.35-39) in the process of creating the expectation of the closure in a specific moment of the musical continuum, shutting down the formal function that was activated up until that moment and indicating a shift towards an expository function ${ }^{14}$. All of the above rhetorically "marks" and highlights this moment of the discourse. If we had to describe the gesture we would have to say that it syntactically elaborates a cadence, but that it rhetorically functions as a gesture that announces the presentation of a theme analogously to the presentation of a character that someone creates by pointing towards the place where it will enter the scene.

To be able to analyze properly the rhetorical function of these kinds of gestures, we must consider the phenomenon of expectation in music. In his book Sweet anticipation, HURON (2006) poses a model which he calls ITPRA, according to the initials of five type of responses that, from a evolutionary perspective, have been developed by humankind in this phenomenon. These responses are of different types: imagination, tension, prediction, reaction and evaluation (appraisal). Out of these responses, the first two occur before an event: we somehow anticipate what will happen (regardles of the subsequent veracity of our anticipation), which implies our imagination; and we feel an increase of tension as we sense that the event is getting "closer". The three responses are activated once the event has happened and it varies according

\footnotetext{
${ }^{11}$ Between the bar 158 and the beginning of the bar 162, Chopin introduces cadential progressions towards the tonic, but they do not resolve the expectation of the I $6 / 4$ since the resolution is expected to be marked towards the dominant. In other words, the chord in $6 / 4$ works as a dominant with a double appoggiatura that is resolved only when the gesture ends over the Eb dominant.

${ }^{12}$ I take the concepts of recession and progression from Wallace Berry, who considers them as processes or courses of action whose tensional load implies the decrease or increase of tension, respectively. These processes can be identified under any parameter and they configure a structural element of first order in the deployment of the form and in the expressivity of music by considering them, even metaphorically, as instances of dissonance (progression) and resolution (recession) (BERRY, 1987, p.7-13).
}

${ }^{13}$ In my analysis I use the concepts of level and formal function. The former corresponds to the temporary expansion in which the formal processes occur, and for my purpose I only need to consider the two levels that are related to the short-term and long-term memory, respectively. I mark the distinction of a micro-level, which corresponds with the connections and processes that take place in the perceptual present, codified by short-term memory with a temporal limit that goes from 4 to 30 seconds, with an average between 4 and 8 seconds, depending on the number of elements that will be remembered (SNYDER, 2009); and I also identify a macro-level, which will start from that limit and go on, becoming a part of long-term memory. With a few exceptions, the gesture that I am studying exists within the macro-level. That is to say, that it can be considered to be a part of the level in which we perceive the musical phrase. The concept of formal function corresponds to the role or to the nature of the participation of sections or segments within the form. The form is understood as a deployment of the structuring processes of the musical discourse (BERRY, 1986, p.403-404). By definition then, the formal functions unfold in the macro-level of form, corresponding to great segments. These constitute five segments: introduction, exposition, transition, development and closure. It is necessary to consider the connection-levels because, strictly speaking, a cadence has the function of closure but in a formal micro-level.

${ }^{14}$ In this sense, I include the distinction that CAPLIN (2004, p.52) makes between the syntactic function of the cadence and the rhetorical function of said segment. The former refers to the process of harmonic and rhythmic closure, while the latter refers to the contributions that the other parameters make in order to conclude the processes. 
to the time that elapses from that moment: "prediction" implicates a response to the forecast that is performed by the imagination; "reaction" is a more automatic or visceral response to the event; and "evaluation" is a response that takes longer to occur (HORDGES and SEBALD, 2011, p.195). From my point of view, the first two responses (imagined anticipation and tension) are the ones that affect more the rhetorical character of the gesture that we are studying, if we consider the subsequent responses to the anticipated event as elements that influence the gestaltic closure of the experience, whether the expectation has a resolution or if the prolongation of the tension remains unsatisfied. But these last two happen in the continuation of the gesture and not within it.

In Figure 3 we can see a diagram of this gesture, including the process of expectation that it provokes, through a more simplified model in contrast with Huron's. As we can see, it consists of the first three moments mentioned by McCreless, which I have indicated as phases. What makes this gesture a perceptive unit is the fact that it configures on its own a gestalt: It is sufficent to itself from the moment that it implicates a complete process of the antecedentconsequent type, with an initiation, a first phase whose function is to initiate the progressive processes, specially in the ascent in the register, prolonging the tension; and a termination, a third phase that includes a descent in the register that is clearly directed towards a goal. This way accelerating the imminent expectation of a resolution of the tension, and a point of arrival accentuated as a limit of the melodic descent.

From the point of view of the parameters involved, the gesture is characterized in the first place by its melodic profile: it always consists of a juxtaposition between an ascent and a descent. Secondly, the descent is perceived as a movement directed towards a goal, an objective perceived as an arrival point, which implies an accent of position ${ }^{15}$, pointing out a shift in the formal function towards an expositive function. Thirdly, from the point of view of the percieved tension, the gesture is characterized by a progressive process, articulated by different parameters, so some of them are able to act compensatorily, and other complementarily. This is a very important fact, because if the process were to be percieved as a progression that is followed by a recession, the effect would be completely different. Fourthly, the fact that the tension is not released up until the point of arrival implies that the gesture carries a model of expectation: it directs the tension towards the final events as a privileged point of resolution of tension. Therefore, I do not think that what follows is a part of the gesture since it is mainly a rethorical way of closing a section and opening another. Therefore, its constitution as a gestaltic unit is exhausted in the moment of arrival, independently of how it carries on.

Regarding the process of expectation, this is configured in an especially clear way in our gesture. To explain it, I have elaborate a simplified model in contrast with Huron's: I only take into account the first three answers of said model which I have adapted to my purpose, understanding them as phases of generation of tension, prediction, and answer to that prediction. The first two occur before the ending of the gesture itself and the third one cannot

\footnotetext{
${ }^{15}$ By accent of position I am referring to a kind of accent that is produced in virtue of its position in the grouping, whether it corresponds to the level of the motif, or to the level or phrase or section. There are two points in a melodic line to which the auditor attributes greater importance since they allow intuiting the structure, unless the conditions of the environment or the syntax state otherwise: the points of beginning and ending. NARMOUR (1988, p.83) explains the reason to consider the beginning and the ending of the linear structures as points of significance: “...melodic structural notes are found at points of initiation and termination. In terms of perception, a point of initiation becomes structural because the listener construes a function of primacy, whereas a point of termination becomes structural because the listener perceives a function in closure."
} 
be defined beforehand since it depends on whether the prediction was confirmed or not. The envolvement of the body in gesture cognition is made especially explicit in the process of generation and continuation of the tension during the gesture, which is indicated in the example with an elongated triangle. This sign reflects that said process is progressive, gradually tensing up until we get to the arrival point (if this is indeed the event that was anticipated). The expectation of this event is the result of the prediction phase, which makes itself evident when the melody starts to descend, giving the feeling of directionality and/or imminent arrival.

This effect is produced by the conjugation of several metaphorical projections whose metaphores are highlited in italics in the figure. "To go up is tense" is a metaphor that comes from our bodily experiences of going up in space, which implies an effort to defeat gravity (especially if we are thinking for instance of jumping). And so it implies the metaphor for "the melody goes up". The fact of jumping and defeating gravity inevitably brings with it the experience of falling, to be pulled down by earth and its gravity, which clearly implies the prediction of a point of arrival in which the energy is disolved. For this process, the concept of "musical force", and specifically Larson's metaphoric idea of "gravity", are particularly relevant, even when he exemplifies it in the level of chord and musical pitch. The above matches very well with the other metaphor: "the movement is directed towards a goal", which comes from the projection that we make music from our bodily experience of directed movement. Gravity and directionality are two fundamental experiences in our life which implicate that our expectation is directed towards the arrival of an objective; that is, a point of arrival, and therefore in the process of "listening as", our feeling of tension gradually increases until we perceive said point ${ }^{16}$. This point is the key that explains why I consider that this gesture only goes until that point, because with respect to the gestalt, said movement completes the process of expectation unless the composer does not immediately resolve this effect.

\footnotetext{
${ }^{16}$ These metaphors are based on the patterns-images of UP-DOWN and ORIGIN, ROAD, GOAL, which are part of the basic schemes that organize our motor and space perception throughout life (JOHNSON, 1990). MARTINEZ (2014, p.89-92) specifically exemplifies the transmission of the schemes that are mentioned above in the interaction of a grown woman and a seven-month-old baby. And, learning from this, a possible self-generation of these schemes in the baby's experience can also be observed.
} 


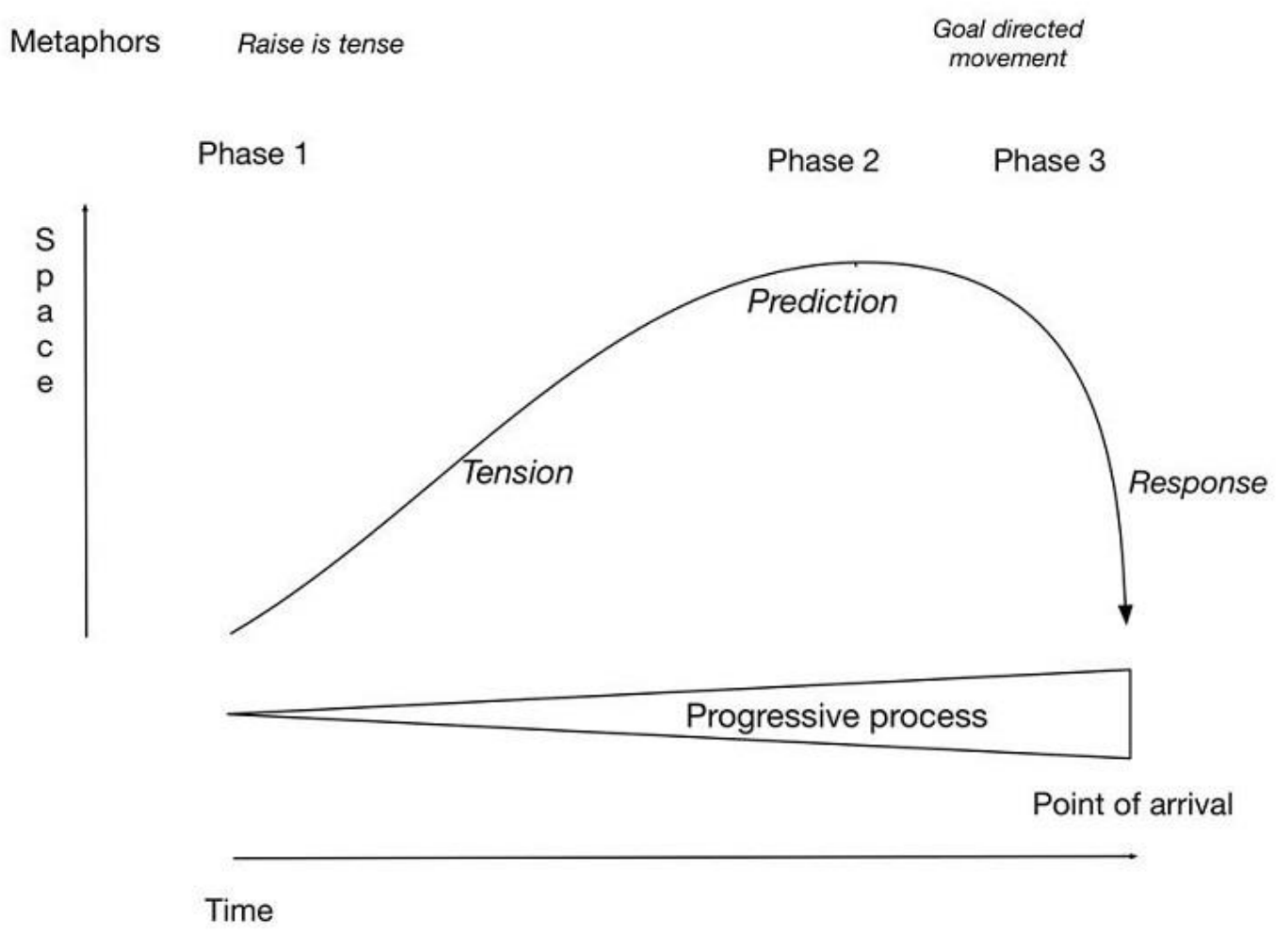

Figure 3: Diagram of the gesture

\section{3 - The gesture in the repertoire: original versions and its variants}

The following are examples of gesture that can be found in intermediate cadences of sonatas for keyboard, for piano, preludes for piano, overtures and symphonies, from Domenico Scarlatti to Debussy. The following five examples are instances of the prototypical version of the gesture, and the other three are variant instances. I have called the versions of the gesture that perfectly match the diagram that we see in Figure 3, "prototypical". That is to say, they clearly represent the three phases, including the point of arrival as a termination of the melodic descent, closing the gesture.

Figure 4 presents the gesture that leads to the first theme of the first movement of Beethoven's Symphony No.1. As we can see, this gesture contains quite clearly, almost in miniature, the three phases that we have talked about: phase one, an ascent, in this case a one-octave dominant; phase two, a stop in the high pitched limit of gesture; and phase three, a quick descent towards the tonic, the point that marks the shift of the formal function. Both the descent from the dominant to the tonic as well as the introduction of 32nd notes, figures that imply a remarkable acceleration from the preceding rhythmic behavior, mark and especially accentuate the beginning of the first theme as a point of arrival of the gesture. I think that this effect is especially remarkable since the dynamic does not involve a progressive process, thus allowing other parameters to come forward as structural elements in the rethorical function of the gesture. 


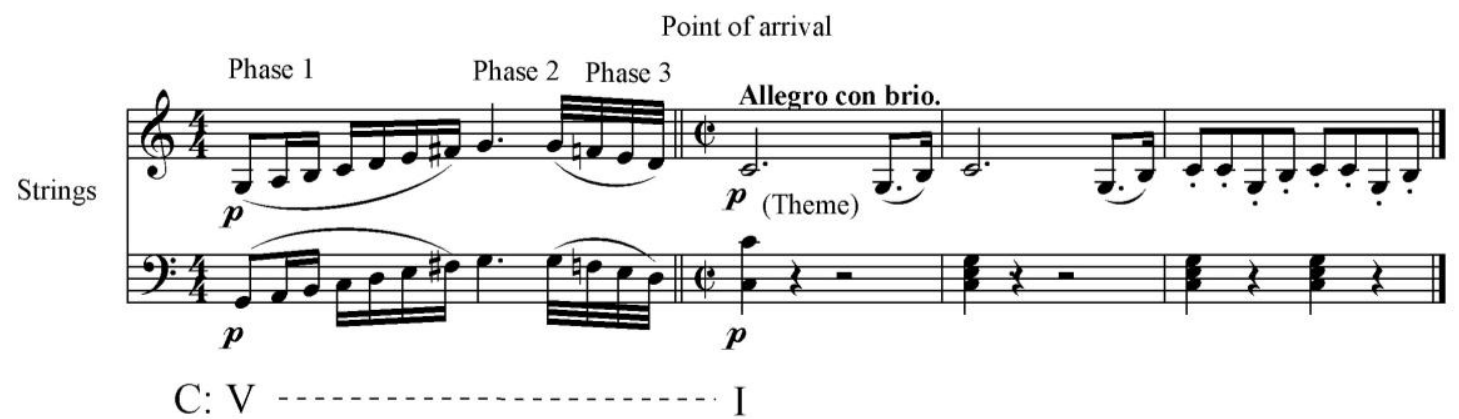

Figure 4: Rhetorical gesture in Beethoven's Symphony No. 1, 1st mov., m.12-15

In the same fashion, Figure 5 shows a particularly representative case. This gesture is produced at the end of the retransition of the first theme of the Allegro of the "Waldstein" Sonata. Phase one covers a harmony of tonic in G major, unlike the previous examples, in which said phase ocurred over a dissonant harmony. What Beethoven does is to displace the dissonant harmony towards phase two, compensating the detention of the ascent in the register by the progression in the tempo-activity, in which the sixteenth note chord is the highest pitched chord. On the other hand, the dynamic is clearly progressive, with a crescendo that stabilizes in phase two in $f$. Giving the accumulation of tension from the nine previous bars, phase three is especially directional since it is percieved as quicker given that it covers more than two octaves in one bar. This part of the gesture metaphorically represents a quick descent towards the resolution of the dominant seventh chord in the E3. The stability of the following segment, indicated by the harmony of the tonic, the recession towards an activity of eighth notes, the switch to the $p p$ dynamic, and the clear re-exposure of the beginning of the main theme clearly mark the shift in the formal function.

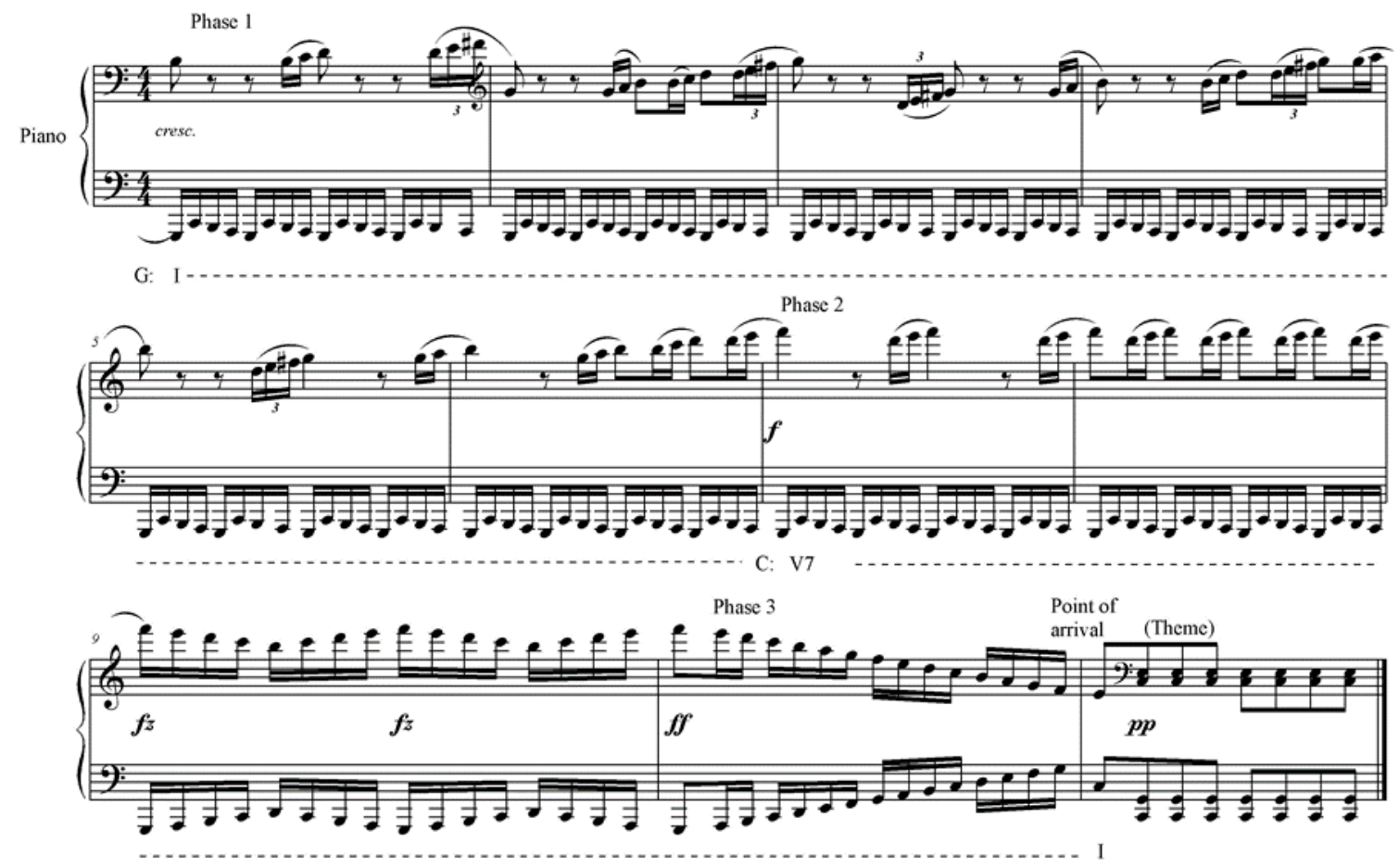

Figure 5: Rhetorical gesture in Beethoven's Sonata op. 53 “Waldstein”, 1st. mov., m.146-156 
Figure 6 shows that our gesture does not belong exclusively to the piano repertoire. We can find it in the second themed area of the Allegro Vivace of Mozart's Symphony No. 40, leading to the closure theme. As we can see, it corresponds harmonically to a cadential progression, extending the passage from I to IV through a chromatic movement in phase one. Said melodic ascent goes from D4 to G5. However, because of the monophony of the wood instruments from phase two, the descent in octaves is especially marked given its breadth, from G6 to Bb4. In my opinion this compensates the lack of a progressive process in the dynamic, which remains $p$ throughout the gesture. Other compensatory elements, in this sense, are rhythm and melodic in profile.

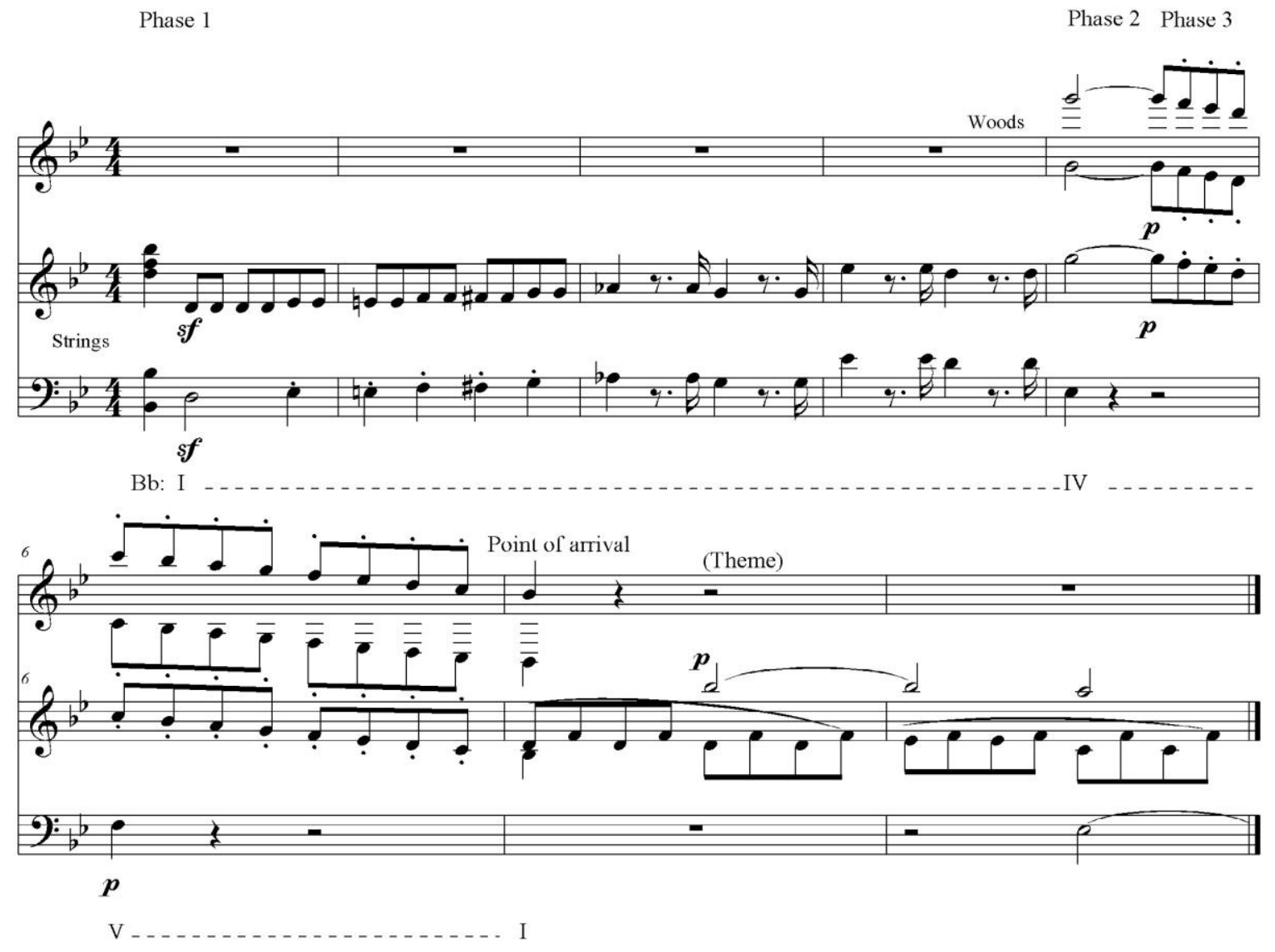

Figure 6: Rhetorical gesture in Mozart's Symphony No. 40, 1st. mov., m.66-72

The gesture begins in a section in which the tactus of the half-note has been blurred, given the syncopations that are established in the previous bars. At the beginning of phase one it continues with the pulsation of eighth notes that comes from the previous bars, until bar 68, which marks the return to the half-note tactus; this is complemented with the introduction of chromatic notes that switch from $\mathrm{D} 4$ to Ab4. That is how the tritone remains in the consciousness of the auditor, especially emphasized by this last pitch, harmonically unstable, giving the tonal context. The detention in the ascent would suggest a melodic compensation in terms of the register; even though the descent resolves the instability of $\mathrm{Ab}$, it does not compensate satisfactorily the register given that it is only a gradual transition. Following that, 
the melody jumps again in an upward direction to D5 and afterwards to G5, thus prolonging the tension. And, as in the previous example, the descent is much shorter than the ascent (two and a half bars in the former against almost four in the latter) but it covers a greater breadth, which affects the directionality of the fragment, helping to highlight $\mathrm{Bb}$ as the point of arrival. Finally, and just like in the previous examples, including Chopin's, the changes that are produced starting from the point of arrival, especially in the level of texture, clearly mark a shift in the formal function.

In spite of the stylistic and aesthetic difference that Wagner's music implies regarding the cases that we have examined so far, Figure 7 presents a version of the gesture that shares the characteristics of the prototype that I have previously pointed out. This gesture is developed in 14 bars with its three characteristic phases.
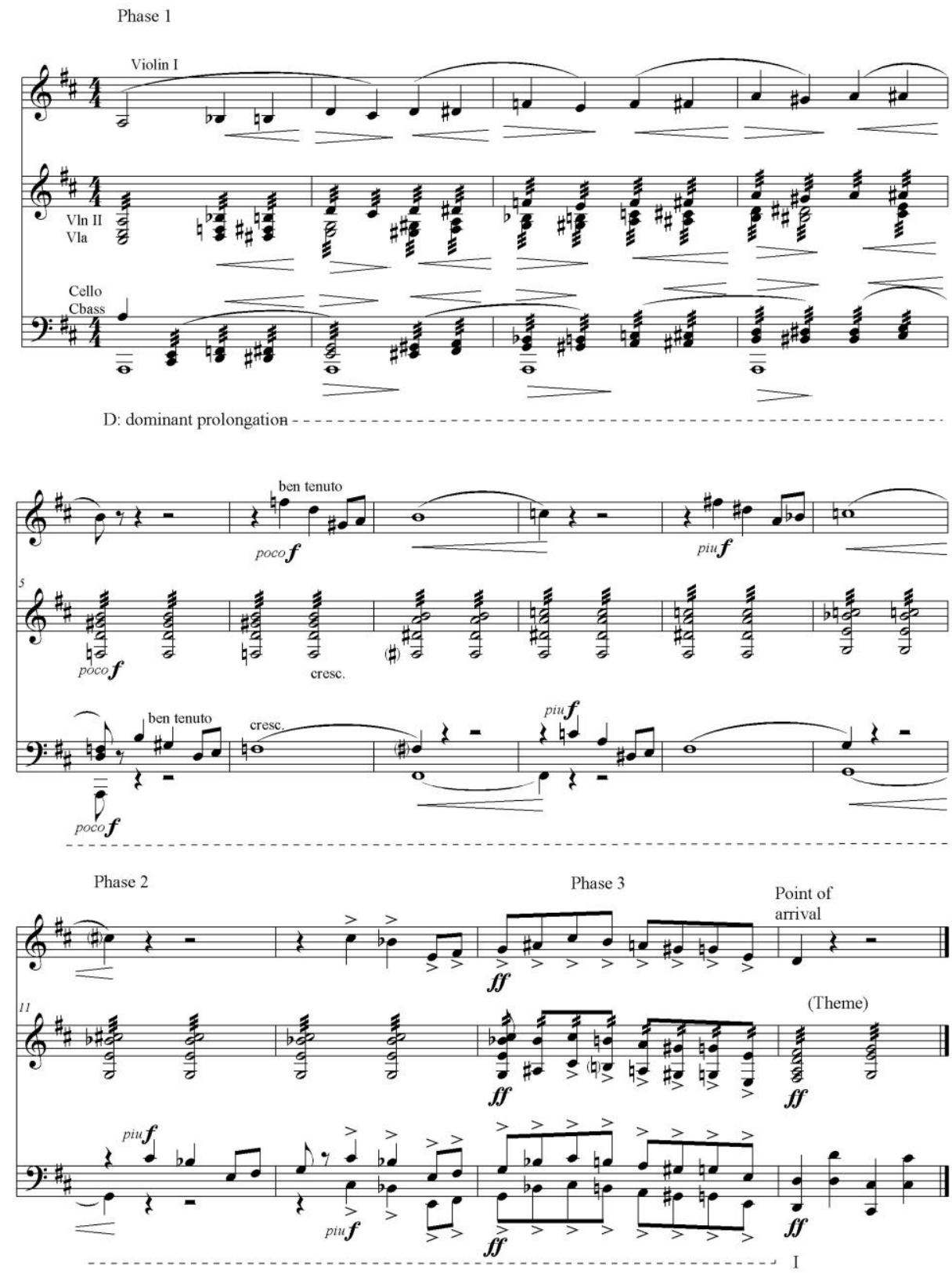

Figure 7: Rhetorical gesture in Wagner's Overture Rienzi, m.34-47 
The ascent begins in A3 in the strings; afterwards this line takes a backseat in the duality of figure-ground perception when the dialogue between the cellos and the first violins is introduced (bar 38). The accompaniment follows the ascent until it is stabilized in phase two in the C\#5 (bar 44), until the descent begins in the second pulse of the bar 46, which is perceived melodically until D4, in which the theme "of the sentence" of the opera is presented again. As in the example of Chopin and the "Waldstein" Sonata, the progression in the dynamic participates in the rhetorical effect, reaching aff shortly before phase three. It is interesting to consider that, while the motivic dialogue that is produced between the cellos and the first violins only contributes to the melodic ascent in a semitone, the feeling of tension produced by the progression in the register is maintained since the first violins play within the high-pitched limit of the register of the gesture. Even when phase three descends from C\#5 and not from F\#5 (the highest musical note of violins), it is perceived as a descent from the high-pitched limit. Besides, and as we have seen in the previous examples, the descent is perceived as being quicker given the fact that it covers a major seventh chord and it is produced in three pulses, contrasting with the slow ascent of 10 bars covering the tenth A3-C\#5.

I thought it would be interesting to leave the following case for the final example of the prototypical versions of the gesture since it has special characteristics (Figure 8). First of all, it occurs in a different language than that of the major-minor tonality, which would correspond to the neo-centric language of Debussy, and the harmony does not act in a way that makes it so relevant in the rhetorical effect of the gesture; secondly, it occurs in a dimension that we could consider to be slightly greater than in the previous example, making it more extensive; thirdly, while we can find phase one, the ascent is not perceived in such a relevant way as it can be found in the previous examples. However, Debussy does use other parameters to accumulate tension.

In my view, this gesture occupies the whole function of transition between the first and the second themes of the Prelude. Phase one is prolonged and the speed of the events is rather slow, in comparison with the previous examples. The ascent is produced by the wide contrast of a motif. As is also the case with the piano music of Debussy, the treatment of texture is complex, establishing three levels: the chords in dotted whole note, while they cover an important part of the register, especially mark the high pitch by representing said boundary; the quarter-note chords that occupy the center of the texture; and the arpeggios in eighth notes in the bass. The ascent is produced especially in the main component of the texture: as I have pointed out in the example, a harmonic motif with a billowy profile of five chords is exposed from bar 16, the one that has the D\# as the highest note. In bar 18 this motif is shortened to three chords, leaving only the ascendant part of the motif, which concludes in the Eb6 at the beginning of bar 19, the point in which this level is merged with the more static level of the chords in the dotted whole notes; later on, if we follow the level of the chords in quarter notes, we can check that the highest pitched notes of the motif, alternately, are the F5 and the G5, but the motif is perceived in a more superior register regarding its last appearance, since it is formed from the Bb4 (previously it was formed from the el F\#4). Bar 22 is crucial for this process: in the higher pitch, the G6 is established as the high-pitched limit, while the motif transposes the G5, leaving the D6 as the highest pitched note (bar 23). As in the examples of Chopin and Mozart, the phase three starts from a highest pitch in contrast to the limit reached by phase two: in this case, the D7. Although the tempo of the descent is not fast, the fact that it is characterized by the same pattern 
that we have found in the previous cases is remarkable, covering a higher register (going from D7 to C1) in a shorter amount of time (four and a half bars against seven and a half in the ascent).
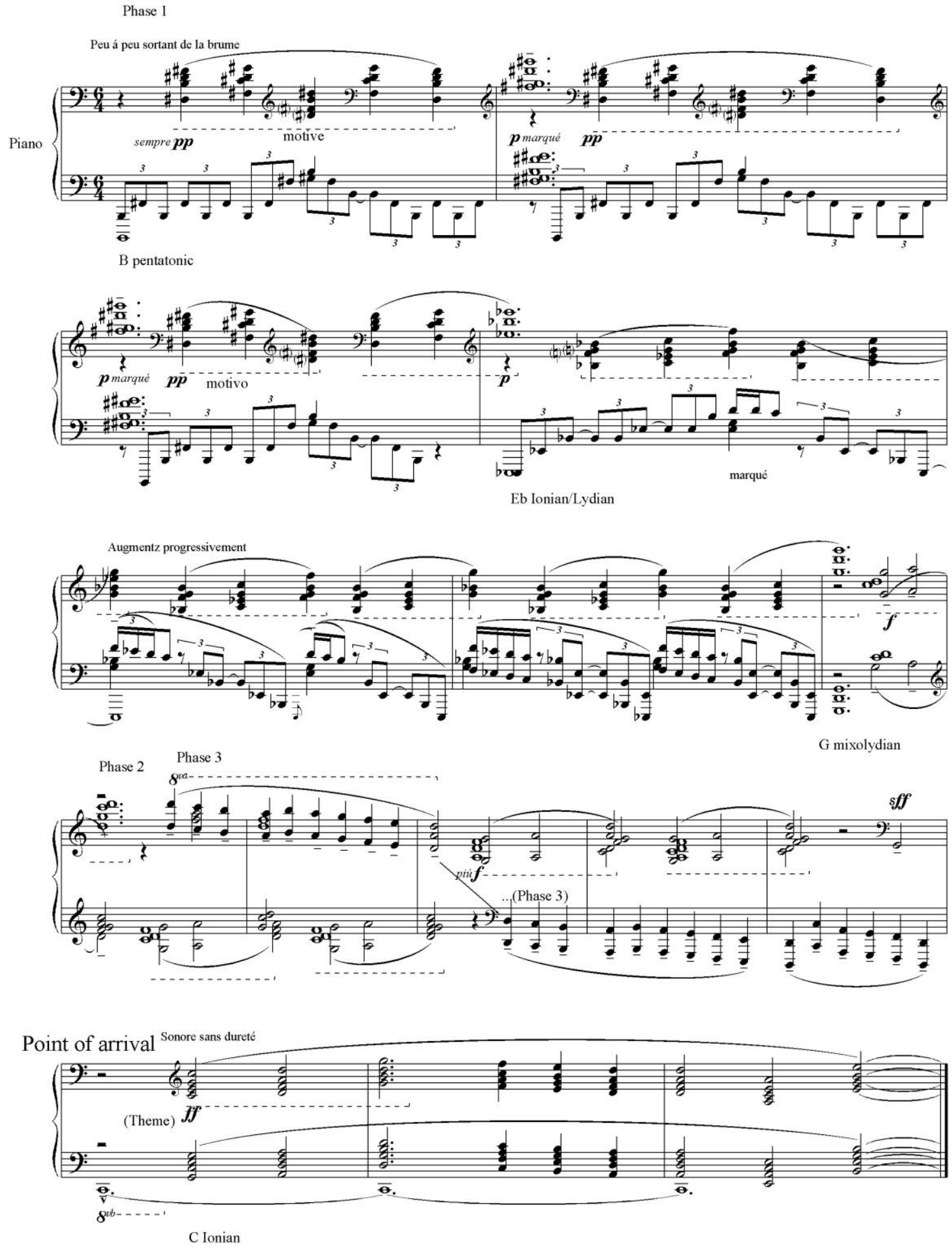

Figure 8: Rhetorical gesture in Debussy's Prelude $X, 1$ st Book, m.16-30 
The activity-tempo and the melodic grouping of the inferior level of the texture compensate for the lack of clarity in the component of the ascent of the gesture, especially reinforcing phase one in terms of the accumulation of tension. Regarding this first parameter, bars 20 and 21 signify a progression to which is added another similar process by the shortening of the melodic grouping: we have heard in four bars a segment consisting of an ascent and a descent in eighth note triplets, which means that the lowest note can be heard in the first pulse of each bar; in the indicated bars, the melodic grouping is shortened, leaving a group that covers half a bar, which results in the lowest note being heard practically twice in each bar. This also contributes to maximize the effect of phase two since the detention of the activity-tempo is produced for a few moments, initiating a recession in said parameter until the end of the gesture. The detention in the highest pitch and in the density of the texture constitutes a change of information that can only generate an expectation: up until now the gesture has been clearly directional, directed towards increasing the tension and, less clearly, directed towards the treble; but, where is the music going?

In my view, this is a clear example of directionality of in phase three in this kind of gesture, since, as it progresses, it starts generating the expectation of a point of arrival that indicates the stabilization in the register and in an expositive function. In fact, the descent "goes through" the texture, switching to the left hand in bar 25. It is interesting to point out the changes in the texture: during the phase three we only have two components and they both present features of regularity. The level of the chords in half notes (which corresponds to the medium level of the gesture) is stabilized in the register since it does not transpose in the motif again, and the descent in octaves has a regular tempo-activity in quarter notes. This recession in the texture allows the descent to $\mathrm{C} 1$ to be perceived as the essential figure phase three.

As I stated above, the harmony does not have a fundamental role in the rhetorical gesture; however, Debussy plays with the major-minor tonality as a stylistic reference. From the point of view of pitch-organization, the gesture uses three different modes (B pentatonic, Eb ionic or lydian, and G mixolydian), whose tonal centers are related by transposition in an incomplete interval-cycle of the kind of interval 4 . The fact that the directional phase of the gesture clearly exposes the G as the tonal center, the G2 that we hear in Sff at the end of the bar 27, and the fact that the gesture leads to the exposition of the second theme whose beginning clearly points out a C ionian, refers analogically to a progression V-I in C major. In this sense, and only by analogy, in the moment that the texture is clarified and the descent towards the tonic begins, the dominant would be introduced, and it would consist of a resolution by signaling the beginning of the theme in $\mathrm{C}$.

The following examples represent variations regarding the prototypical gesture. This implies a certain difference with the reference, but slightly less-so in the sense that they do not transform the gesture into something different. They are different in the sense that they present an extension of phase three by delaying the rhetorical point of arrival, prolonging phase three or separating the melodic point of arrival from the rhetorical.

Figure 9 shows a variant of the gesture that clearly presents the characteristics that I have just described. In this case, phase two is absent from the moment in which a detention in the highpitched register does not take place, however the rhetorical process is quite similar to the previous examples, with an ascent and a descent that are clearly directional. The variant is 
produced because the note that should mark the point of arrival is not rhetorically reached until bar 47 as part of the melody. The auditor perceives that the descent continues in bar 46 , despite having already reached D4 at the end of the previous bar. It is as if a bar separating the descent from phase three and the point of arrival has been introduced. This extension of the phase has the rhythmical effect of slowing down the momentum, which increases the tension because, from the point of view of the register and the harmony, we have not reached the conditions of stability that we expected. In this sense, the harmonic progression with the dominant with a double appoggiatura and the dominant seventh resolving towards the tonic in bar 47 reinforces the process of expectation and resolution. As we can see again, the arrival to the tonic marks a shift in the formal function.

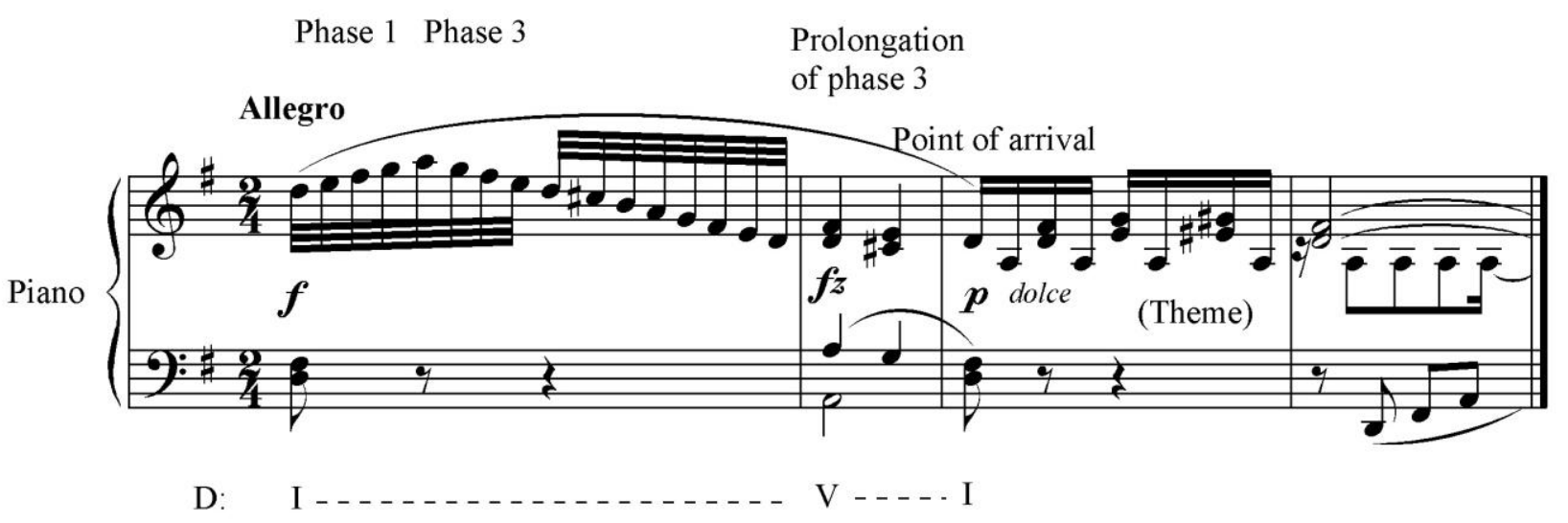

Figure 9: Rhetorical gesture in Beethoven's Sonata Op. 14, No. 2, 1st. mov., m.45-48

The last two examples show a different way of delaying the conclusion of the gesture and the gestalt-like closure. Figure 10, dating to the 1740s, is the oldest case of gesture that presented here. The rhetorical strategy is a bit different: while the final point of arrival is delayed, this is, however, achieved by the separation of the melodic point of arrival from the rhetorical. The termination of the melodic descent is unequivocally achieved in bar 35, but with a trill that continues with the prolongation of the dominant, which covers the totality of the gesture. This point is also especially marked by the fermata. The tension remains, only being resolved by the chord of A minor and an expositive function in bar 36. 


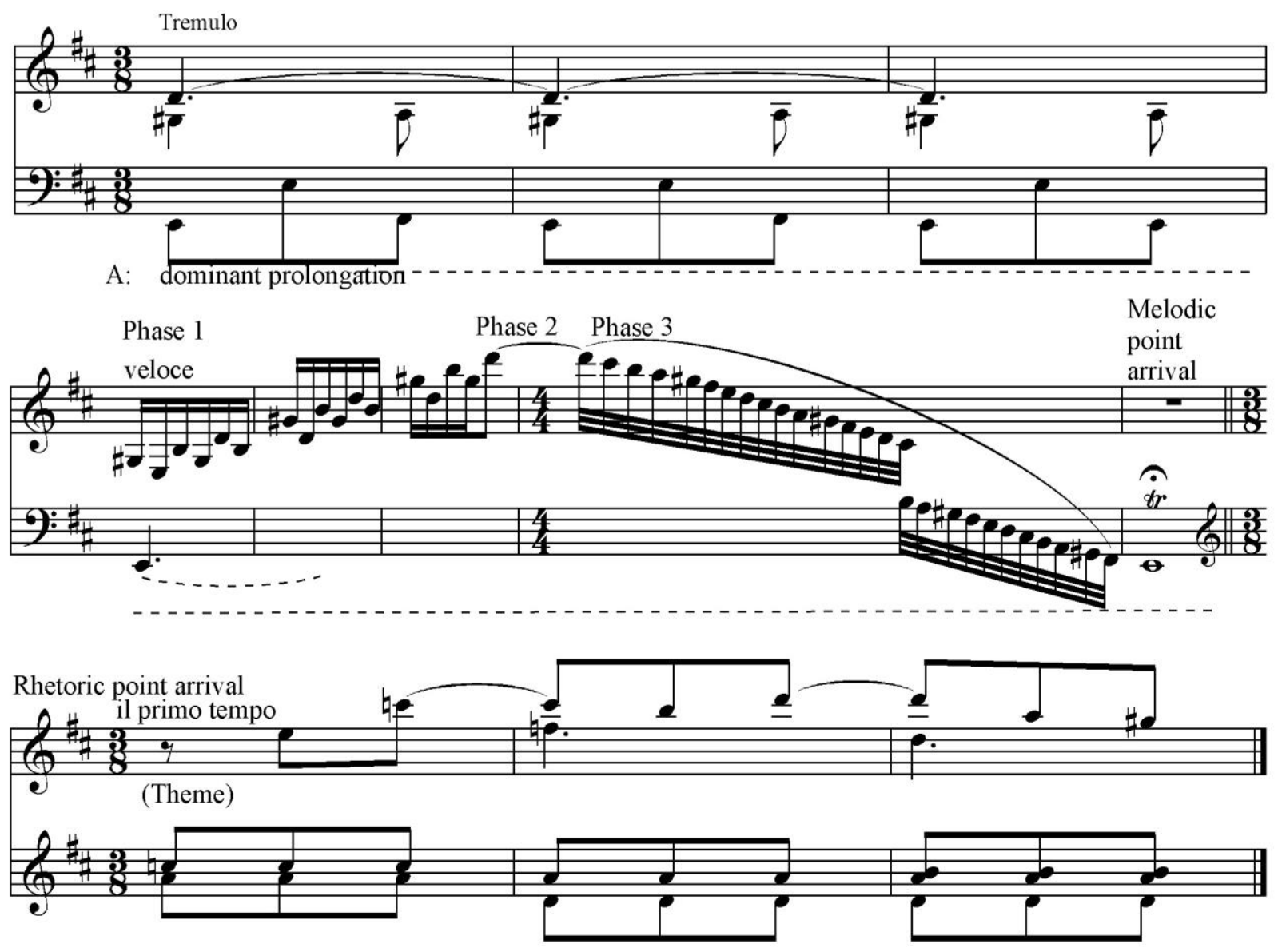

Figure 10, Rhetorical gesture in Domenico Scarlatti's Sonata k. 119, m.28-38

The last example (Figure 11) corresponds to the gesture that closes the thematic introduction of the first movement of Dvorak's Symphony No. 8. This case is kindred to Debussy's, since it separates two sections that present expositive functions: phase one is composed over an extension of the dominant of G major, ascending from D4 until the movement is stabilized in phase two in E6 (although harmonically the D6 stands out). Phase two is extended by three bars, accompanied at the interior of the texture by an imitative motif (dotted eighth-note and sixteenth-note), which is taken by the melody in phase three and used to descend until said movement is concluded with a rhythmic septuplet, which accelerates the feeling of movement even more. However, at this point the melody goes back to D4 (the same point as the initiation of the ascent) without resolving the harmonic tension, justifying the 3 D's in octaves that accentuate the weak beat of the bar, since they draw the attention of the auditor to an immediate future by introducing a metric irregularity. Thus, Dvorak extends the resolution of the expectation of a stable point of arrival, postponing the arrival to the tonic and to a new theme in a bar, separating the melodic and rhetorical points of arrival ${ }^{17}$.

\footnotetext{
${ }_{17}$ The author thanks Professor Michael Cooper for his work in translation end editing of the final research document.
} 
Phase 1

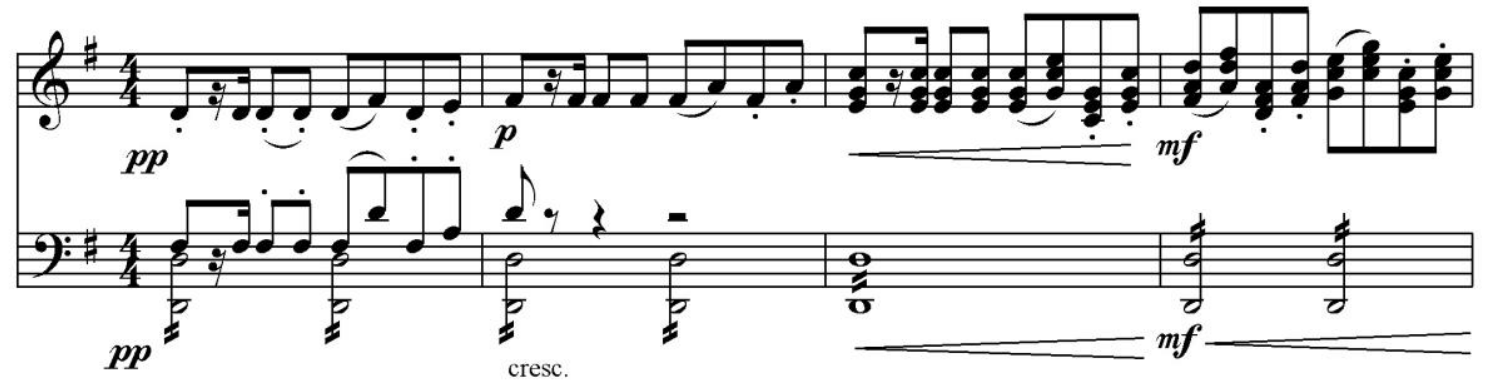

G: dominant prolongation- $\ldots \ldots \ldots \ldots \ldots$
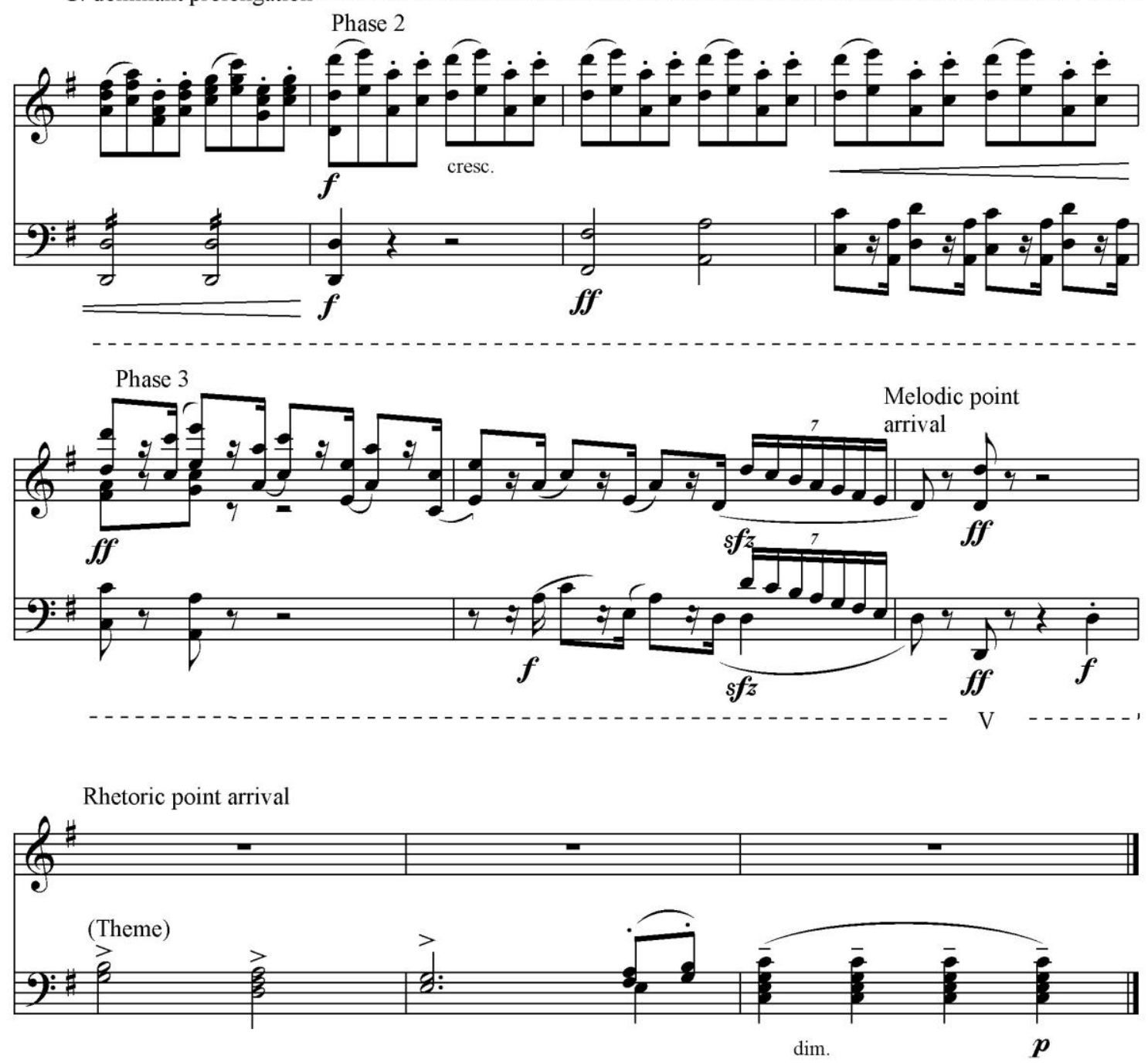

Figure 11: Rhetorical gesture in Dvorak's Symphony No. 8, 1st mov., m.28-41

\section{4 - Conclusions}

Throughout this article, I have resorted to the ideas of embodied cognition to explain the cognitive efficiency of the gesture that we have studied and its rhetorical function. I have analyzed the gesture as a complete perceptive unit, with an initiation, a middle and a 
termination, each of its parts conceptualized as phases, describing it also as a model of expectation with three phases, from which the first two elapse before the end of the gesture: tension, prediction and response. As I have demonstrated, the gesture presented by McCreless is a variant of the gesture that we studied in this article from the moment it differentiates itself only by the phase of the response. From the nine presented examples, eight include a harmonic model characteristic of the cadential processes: dissonance followed by consonance, or tension and resolution. The places of the harmonies and the extension of the tension of course vary, but they all lead to the resolution, whether it is at the interior of the gesture (in the point of arrival) or in the immediate continuation of phase three. They all imply a remarkable shift of the formal function. From the point of view of the parameters involved, there is only one element that stays constant: the ascent and descent in the register, but some highly progressive process always remains in one or several parameters until the point of arrival. Lastly, and given the stylistic variability of the gesture shown in the example of Debussy, we can conclude that its rhetorical efficiency is not due to a specific language but to its progressive and directional characteristics that were achieved using secondary parameters.

\section{References}

1. AGAWU, K. (2012). La música como discurso. Aventuras semióticas en la música romántica. Trad. S. Villegas. Buenos Aires: Eterna Cadencia.

2. BEN-TAL, O. (2012). Characterising musical gestures. Musicae Scientiae . n.3, v. 16, p.247-261.

3. BERRY, W. (1986). Form in Music. 2d. ed. New Jersey: Prentice-Hall.

4. _ (1987). Structural Functions in Music. New York: Dover.

5. LÓPEZ CANO, R. (2012). Música y retórica en el barroco. 2d. ed. Barcelona: Amalgama Edicions.

6. CAPLIN, W. E. (2004). The Classical Cadence: Conceptions and Misconceptions. Journal of the American Musicological Society. n.1, v. 57, p.51-118.

7. COX, A. (1999). The metaphoric logic of musical motion and space. Ph. D. Dissertation: University of Oregon.

8. _ (2006). Hearing, Feeling, Grasping Gestures. In: Gritten, A., and King, E. (Eds.), Music and Getsure. Farnham: Ashgate.

9.___ (2011). Embodyng Music: Principles of the Mimetic Hypothesis. Music Theory Online. n.2, v.17, p.1-24.

10. DUDEQUE, N. (2013). Gestos musicais na Peça para Piano Op. 11, No 3 de Arnold Schoenberg. Musica Hodie. n.2, v.13, p.85-98.

11. FLUSSER, V. (2014). Gestures. Trad. N. A. Roth. Minneapolis: University of Minnesota Press.

12. GRITTEN, A., and KING, E. (2006). Introduction. In: Gritten, A. and King, E. (Eds.), Music and Gesture. Farnham: Ashgate.

13. HATTEN, R. (2004). Interpreting Musical Gestures, Topics, and Tropes. Mozart, Beethoven, Schubert. Bloomington: Indiana University Press.

14. (2005). Four Semiotic Approaches to Musical Meaning: Markedness, Topics, Tropes, and Gesture.

Muzikoloski zbonik. n.1, v.41, p.5-30. 
15. (2006). A Theory of Musical Gesture and its Application to Beethoven and Schubert. In: Gritten, A. and King, E. (Eds.), Music and Gesture. Farnham: Ashgate.

16. HORDGES, D. A., and SEBALD, D. (2011). Music in the Human Experience. An introduction to music psychology. New York: Routledge.

17. HURON, D. (2006). Sweet anticipation. Music and psychology of expectation. Cambridge: The Massachusetts Institute of Technology.

18. KÚHL, O. (2011). The semiotic gesture. In: Gritten, A. and King, E. (Eds.), New Perspectives on Music and Gesture. Farnham: Ashgate.

19. LARSON, S. (2006). Musical Gestures and Musical Forces: Evidence from Music-Theoretical Misunderstandings. In: Gritten, A. and King, E. (Eds.), Music and Gesture. Farnham: Ashgate.

20. (2012). Musical Forces. Motion, Metaphor, and Meaning in Music. Bloomington: Indiana University

Press.

21. MARTINEZ, I. C. (2014). La base corporeizada del significado musical. In: Español, S. (Comp.). Psicología de la música y del desarrollo. Buenos Aires: Paidós.

22. MCCRELESS, P. (2006). Anatomy of a Gesture: from Davidovsky to Chopin and Back. In: Almén, B. and Pearsall, E. (Eds.), Approaches to Meaning in Music. Bloomington: Indiana University Press.

23. MEYER, L. B. (2000). El Estilo en la Música. Teoría Musical, Historia e Ideología. Madrid: Pirámide.

24. NARMOUR, E. (1988). Melodic structuring of harmonic dissonance. A method for analysing Chopin's contribution to the development of harmony. In: Samson, J. (Ed.), Chopin Studes. Cambridge: Cambridge University Press.

25. NATTIEZ, J.-J. (1990). Music and Discourse: Toward a Semiology of Music. Princeton: Princeton University Press.

26. PISTON, W. (1998). Armonía. Cooper City: Span Press Universitaria.

27. SNYDER, B. (2009). Memory for Music. In: Hallam, S., Cross, I, and Thaut, M. The Oxford Handbook of Musica Psychology. Oxford: Oxford University Press.

28. SPITZER, M. (2004). Metaphor and Musical Thought. Chicago: The University of Chicago Press.

\section{References of music scores}

1. BEETHOVEN, Ludwig van (1989). Symphonie $\mathbf{N}^{\circ}$ 1, op. 21. New York: Dover Publications, Inc, p.2.

2. (1999). Piano Complete. Sonate II. Budapest: Könemann Music Budapest, p.104-105.

3. (1999). Piano Complete. Sonate I. Budapest: Könemann Music Budapest, p.193-194.

4. CHOPIN, Frédéric (1915). Complete Works for the Piano, Vol. 5. New York, G. Schirmer, p.708-709.

5. DEBUSSY, Claude (1910). Préludes, 1er. Livre. Paris: Durand et Cie., p.39.

6. DVORÁK, Antonin (1984). Symphonies Nos. 8 and 9 ("New World”) in full scores. New York: Dover Publications, Inc, p.6-8.

7. MOZART, Wolfgang A. (1880). Wolfgang Amadeus Mozarts Werke, Serie VIII: Symphonien, Bd.3, No.40. Leipzig: Breitkopf und Härtel, p.4-5. 
8. SCARLATTI, Domenico (1978). Domenico Scarlatti : Sonates, Volume 3. Paris: Heugel, p.72-73.

9. WAGNER, Richard (1896). Rienzi, der Letzte der Tribunen. Ouverture. Berlin: Adolph Fürstner, p.7-9.

Note about the author

Gonzalo Javier Martínez García holds a Doctor in Music from the Autonomous University of Madrid and is a professor of analysis and harmony in the Musical School of the University of Talca. His principal areas of interest are in historical musicology and musical analysis. He is the author of the recently published Aspects to Twentieth-Century Music. 